\title{
Overexpression of (At)NPR1 in Rice Leads to a BTH- and Environment-Induced Lesion-Mimic/Cell Death Phenotype
}

\author{
Heather A. Fitzgerald, ${ }^{1}$ Maw-Sheng Chern, ${ }^{1}$ Roy Navarre, ${ }^{2}$ and Pamela C. Ronald ${ }^{1}$ \\ ${ }^{1}$ Department of Plant Pathology, University of California, Davis 95616; ${ }^{2}$ United States Department of Agriculture-Agricultural \\ Research Service, Prosser, WA 99350, U.S.A.
}

Submitted 3 July 2003. Accepted 11 October 2003.

Systemic acquired resistance (SAR) is an inducible defense response that protects plants against a broad spectrum of pathogens. A central regulator of SAR in Arabidopsis is NPRI (nonexpresser of pathogenesis-related genes). In rice, overexpression of Arabidopsis NPR1 enhances plant resistance to the bacterial pathogen Xanthomonas oryzae pv. oryzae. This report demonstrates that overexpression of (At)NPR1 in rice also triggers a lesion-mimic/cell death (LMD) phenotype. The LMD phenotype is environmentally regulated and heritable. In addition, the development of lesions and death correlates with the expression of rice defense genes and the accumulation of hydrogen peroxide. Application of the salicylic acid (SA) analog, benzo(1,2,3) thiadiazole-7-carbothioc acid S-methyl ester (BTH), potentiates this phenotype. Endogenous $\mathrm{SA}$ levels are reduced in rice overexpressing (At)NPR1 when compared with wildtype plants, supporting the idea that (At)NPR1 may perceive and modulate the accumulation of SA. The association of $(A t) N P R 1$ expression in rice with the development of an LMD phenotype suggests that (At)NPR1 has multiple roles in plant stress responses that may affect its efficacy as a transgenic tool for engineering broad-spectrum resistance.

Plants defend themselves against pathogen attack by stimulating multiple signaling pathways. The defense response generated by the induction of these pathways can be specific against a particular pathogen, as is the case for resistance (R)-gene-mediated resistance, or general against a broad spectrum of pathogens. The systemic acquired resistance (SAR) response falls into the latter category and is one of the best described defense responses in plants, particularly dicotyledons (Ryals et al. 1996). After recovery from an initial inoculation with an avirulent pathogen, plants that exhibit SAR are able to resist secondary infection by the same, or distinct, pathogens. SAR is characterized by broadspectrum resistance to viral, bacterial, and oomycete pathogens and also is associated with localized necrosis (Ryals et al. 1996). Plant infections often are associated with a rise in endogenous salicylic acid (SA) levels, both near the site of infection and in distal plant organs (Malamy et al. 1990; Metraux et al. 1990). In addition, exogenous application of SA or its chemical analogs, such as benzo(1,2,3)-thiadiazole7-carbothioc acid (BTH), triggers SAR in dicots and monocots (Friedrich et al. 1996; Gorlach et al. 1996; Lawton et al. 1996; Metraux et al. 1990; Morris et al. 1998). Removal of

Corresponding author: Pamela Ronald; E-mail: pcronald@ucdavis.edu

* The $\boldsymbol{e}$-Xtra logo stands for "electronic extra" and indicates Figure 4 appears in color online.
SA by the bacterial NahG enzyme (encoding a salicylate hydroxylase that converts SA to catechol) renders transgenic plants incapable of mounting a SAR response (Gaffney et al. 1993; Vernooij et al. 1994). Along with elevation of SA levels, the increased expression of pathogenesis-related (PR) genes also has been tightly correlated with the onset of SAR. Several PR genes encode proteins that function as chitinases and $\beta-1-3$ glucanses and are predicted to act directly as antimicrobial agents (Maleck et al. 2000; Ward et al. 1991).

Genetic screens based on the correlation between PR gene expression and plant defense responses have isolated genes important for transducing the SAR response. In one such screen, a mutant with reduced $P R-2$ expression was shown to have an alteration in the Arabidopsis NPRl gene (also known as NIMI and SAII) (Cao et al. 1994; Ryals et al. 1997; Shah et al. 1997). Subsequent experiments have indicated that (At)NPRl is a key mediator of SAR. Arabidopsis nprl mutants are impaired in their ability to induce a SAR response, even after exogenous application of SA, and display enhanced susceptibility to diverse pathogens (Cao et al. 1997; Ryals et al. 1997). In addition, overexpression of (At)NPRI in Arabidopsis leads to enhanced pathogen resistance in a dosedependent manner (Cao et al. 1998). (At)NPRl encodes a protein that contains ankyrin repeats and shows limited overall sequence similarity to the immune response regulator IKB (Cao et al. 1997; Ryals et al. 1997). Arabidopsis overexpressing (At)NPR1 do not display obvious morphological alterations; however, they have enhanced sensitivity to SA and BTH (Cao et al. 1998; Freidrich et al. 2001). (At)NPRl overexpression and enhanced resistance also are correlated with both elevated and quicker $P R$ gene expression, suggesting that (At)NPRl regulates transcription (Cao et al. 1998; Freidrich et al. 2001). This may occur after (At)NPR1 is localized to the nucleus, where it is able to interact with the TGA family of basic-leucine zipper (bZIP) transcription factors (Fan and Dong 2002; Kinkema et al. 2000; Subramaniam et al. 2001; Zhang et al. 1999). Recent studies indicate that the nuclear localization of (At)NPR1 is dependent on the molecular state of the protein. When SAR is triggered and SA levels increase, the cytosolic redox environment may be altered, resulting in the reduction of intermolecular sulfide bonds that normally keep (At)NPR1 present in the cytosol in an oligomeric form. Once these bonds are reduced, (At)NPR1 is found in a predominantly monomeric form that can translocate into the nucleus (Mou et al. 2003). Therefore, the SAR response is mediated by (At)NPR1 in a complex manner involving its ability to sense and respond to changing cellular SA and redox levels.

The interest in engineering genes such as (At)NPRl (or its homologs) into agronomically important plant species has 
increased as the tools for identifying genes conferring resistance, and transferring them into crops, have developed. However, the extent of conservation for the SAR pathway between dicots and monocots is not yet known. SAR is documented clearly in dicots, and studies in wheat and maize reveal that BTH application can induce varying levels of disease resistance in monocots (Gorlach et al. 1996; Morris et al. 1998). In rice, studies with SA analogs and pathogens have demonstrated the existence of SAR-like pathways. For example, BTH treatment of rice seedlings induces resistance to the fungal pathogen Magnaporthe grisea and accumulation of defense gene transcripts (Oostendorp et al. 2001; Schweizer et al. 1999). One of the most compelling examples of a monocot SAR-like response is the enhanced resistance to $M$. grisea that can be demonstrated following an infection with the nonhost pathogen Pseudomonas fluorescens (Smith and Metraux 1990). However, in rice, unlike most other plants, high levels of endogenous SA are detected even under noninducing conditions. Basal SA levels also are not elevated after infection with pathogens, thus obscuring the role of SA in any SAR-like responses in rice (Chen et al. 1997; Silverman et al. 1995). Although the role of SA is unclear, other downstream components of the SAR pathway in rice are likely to be functional. This idea is supported by data demonstrating that overexpression of $(A t) N P R l$ in rice confers resistance to the bacteria pathogen Xanthomonas oryzae pv. oryzae and that (At)NPR1 interacts with rice TGA transcription factors (Chern et al. 2001).

Genetic mutant screens for plants with enhanced resistance to pathogens have identified several components of rice disease-resistance signaling pathways. Many of these mutants (e.g., $s p l$ and $c d r$ mutants) have heightened pathogen resistance but also display a lesion-mimic/cell death (LMD) phenotype (Kiyosawa 1970; Takahashi et al. 1999; Yin et al. 2000). The LMD phenotype is associated with the formation of necrotic spots resembling infection on leaf tissue. Lesions can occur spontaneously, but usually develop after abiotic or biotic stress. The extent of necrosis in lesion-mimic plants depends on the environmental growth conditions. In severe cases, the necrosis is uncontrollable, resulting in leaf collapse and plant death (Dietrich et al. 1994; Gray et al. 2002; Kiyosawa 1970). A spontaneous cell death phenotype is induced by mutations in the barley gene Mlo, which encodes a transmembrane protein, and by mutations in the maize Lls 1 gene, which encodes a novel protein that may be involved in phenolic detoxification or chlorophyll $b$ biosynthesis (Buschuges et al. 1997; Gray et al. 1997, 2002). Lesion-mimic mutants also have been observed in dicots and frequently fall into one of two classes, either initiation or propagation mutants (Lorrain et al. 2003). Several lesion-mimic mutants, isolated as suppressors of nprl-5 SA insensitivity, fall into the initiation class. These include mutants with alterations in the ssi (1,2, and 5) genes. One well-studied propagation mutant was determined to have an alteration in $L S D 1$, a gene encoding a zinc-finger protein that has putative effects on transcription. The $l s d l$ mutation allows uncontrolled, spreading cell death and is sensitive to SA analogs (Dietrich et al. 1994; Jabs et al. 1996; Shah et al. 1999, 2001; Shirano et al. 2002).

Although manipulation of many defense components can lead lesion-mimic phenotypes, no such effects have been attributed to (At)NPRI manipulation in Arabidopsis In this report, we demonstrate that $(A t) N P R 1$ overexpression (NPR1-OX) in rice leads to an LMD phenotype. Lesion formation occurs in specific environmental conditions, and is potentiated strongly by treatment with $\mathrm{BTH}$. The rice LMD phenotypes are heritable and correlate with the increased expression of several rice defense-associated genes. NPR1-OX plants dis- playing lesions show increased accumulation of hydrogen peroxide $\left(\mathrm{H}_{2} \mathrm{O}_{2}\right)$ and reduced $\mathrm{SA}$ levels when compared with their wild-type counterparts. The lesion development and death associated with $(A t) N P R I$ overexpression occur in environments with altered light regimens. Together, these observations illustrate undesirable effects associated with overexpressing $(A t) N P R l$ in rice grown under particular environmental conditions.

\section{RESULTS}

\section{Rice overexpressing (At)NPR1 display}

an environmentally controlled, LMD phenotype.

In previous work, constitutive overexpression of the (At)NPRl gene was demonstrated to enhance rice resistance to the bacterial pathogen, $X$. oryzae pv. oryzae (Chern et al. 2001). To determine if (At)NPRI-mediated resistance to $X$. oryzae pv. oryzae could be increased further, (At)NPRI overexpressing rice (NPR1-OX) was treated with the SARinducing chemical, BTH. Healthy NPR1-OX rice plants, grown for 6 weeks in the greenhouse, were transferred to a growth chamber and treated with $\mathrm{BTH}$ prior to inoculation with $X$. oryzae pv. oryzae. Three days after treatment, the newly expanding leaves of these plants displayed a lesion-like necrosis that spread along the central leaf vein and in older leaves, and the tissue wilted and became chlorotic or died. This phenotype occurred specifically in NPR1-OX plants and was not observed in the wild-type cultivar, TP309 (Fig. 1A). Furthermore, NPR1-OX plants that were not treated with BTH also developed necrotic lesions and had increased rates of
A

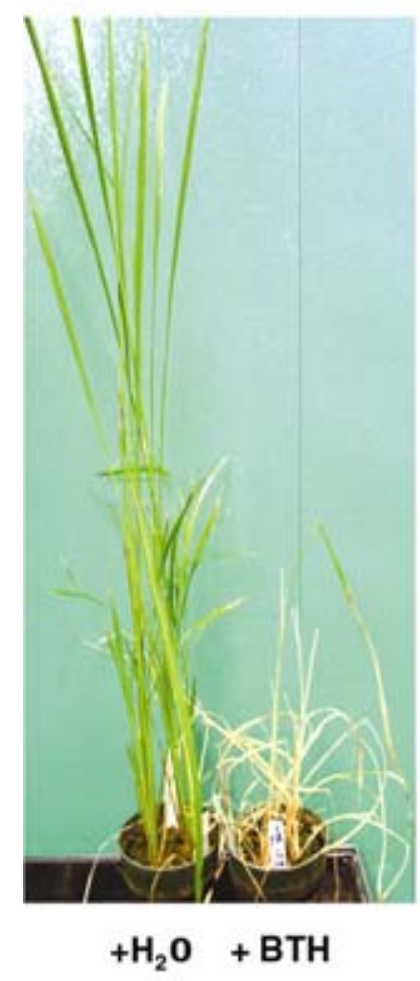

B

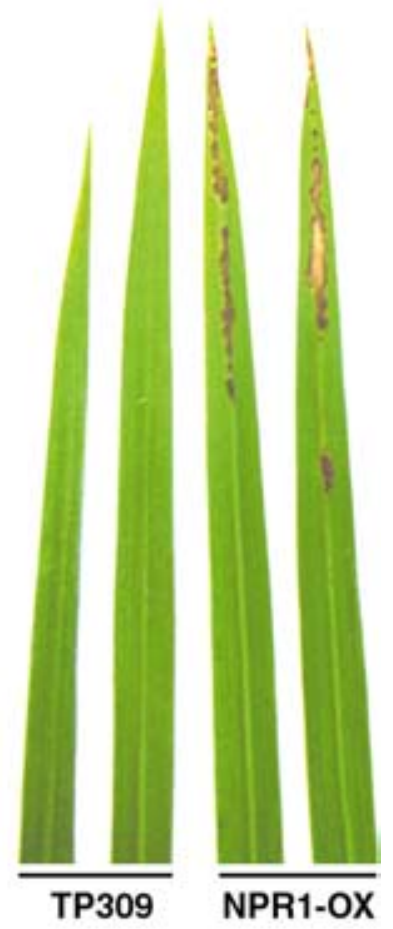

Fig. 1. Lesion-mimic/cell death phenotypes of NPR1-OX rice plants. A, Cell death phenotype of 6-week-old NPR1-OX plants after treatment with water or $10 \mathrm{mM}$ benzo(1,2,3)-thiadiazole-7-carbothioc acid (BTH). Picture was taken 4 weeks posttreatment. B, Lesion phenotype of NPR1OX plants grown under growth-chamber conditions (12-h day and night cycle, $28^{\circ} \mathrm{C}, 90 \%$ relative humidity) for 2 weeks. TP309 was the recipient cultivar for (At)NPR1 transformation. 
mature leaf death. The extent of necrosis and leaf death in nontreated NPR1-OX plants was similar to treated plants but the phenotype appeared more slowly; lesions were apparent only after plants were grown in the growth chamber for at least 3 weeks (Fig. 1B). These results indicate that (At)NPRI overexpression in rice can initiate a lesion-mimic phenotype and leaf death (the LMD phenotype). The LMD phenotype is potentiated by BTH treatment and occurs only in particular growing environments.

\section{Lesions and cell death in NPR1-OX rice are potentiated by BTH treatment at all developmental stages.}

In initial experiments to test whether or not BTH could enhance $(A t) N P R 1$-mediated $X$. oryzae pv. oryzae resistance, the LMD phenotype was observed in 6-week-old rice plants treated with high levels of BTH $(10 \mathrm{mM})$. Further experiments were performed to determine the minimal BTH concentration required to potentiate the LMD phenotype and to investigate whether or not lesion development was age dependent. Sixweek-old plants were treated with concentrations of BTH

Table 1. Quantitation of the lesion-mimic/cell death (LMD) phenotype ${ }^{a}$

\begin{tabular}{lcc}
\hline & \multicolumn{2}{c}{ Number of plants displaying LMD phenotype } \\
\cline { 2 - 3 } Genotype & $\mathbf{+ H}_{\mathbf{2}} \mathbf{O}$ & $\mathbf{+ B T H}^{\mathbf{b}}$ \\
\hline TP309 & $0 / 39$ & $0 / 35$ \\
NPR1-OX & $3 / 42$ & $42 / 42$ \\
\hline
\end{tabular}

${ }^{a}$ Plants were grown in a growth chamber until 4 weeks old. Plants were scored for phenotypes 2 weeks posttreatment. The experiment was repeated three times with similar results.

${ }^{\mathrm{b}} \operatorname{Benzo}(1,2,3)$-thiadiazole-7-carbothioc acid. ranging from 0.01 to $10 \mathrm{mM}$. A dose-dependent response was observed in the BTH-treated NPR1-OX plants (Fig. 2A). The phenotypes of NPR1-OX treated with $0.01 \mathrm{mM}$ BTH were similar to water-treated NPR1-OX plants. Plants from the control cultivar, TP309, did not display any lesions or death. These effects have been analyzed quantitatively and a representative experiment is shown in Table 1. Two weeks after BTH treatment, all NPR1-OX plants developed a clear LMD phenotype. Approximately $10 \%$ of water-treated NPR1-OX plants also developed lesions after 2 weeks of growth in the growth chamber, this proportion increased to $100 \%$ if the plants were kept in the growth chamber for 4 weeks.

The LMD phenotype appeared under growth chamber conditions; therefore, attempts were made to trigger the LMD symptoms in the greenhouse by treating NPR1-OX and TP309 plants with BTH (in concentrations ranging from 10 to $50 \mathrm{mM}$ ). Lesion formation was not observed on any plants, although NPR1-OX plants had an increased number of mature leaves that became chlorotic and died. In general, both NPR1-OX and TP309 plants remained healthy and green and yielded seed (data not shown). Therefore, (At)NPRl overexpression was necessary, but not sufficient, to induce lesions, and increasing the concentration of BTH enhanced lesion formation and leaf death.

To determine whether or not the LMD phenotype was age dependent, NPR1-OX plants ranging from 2 to 8 weeks old were transferred to the growth chamber and treated with either water or BTH. The LMD phenotype occurred in all ages of plants tested, although old and young plants differed in whether or not necrotic lesions or premature senescence were the predominant symptoms. In older ( $>5$ weeks) NPR1OX plants, lesion development was prevalent on young
A

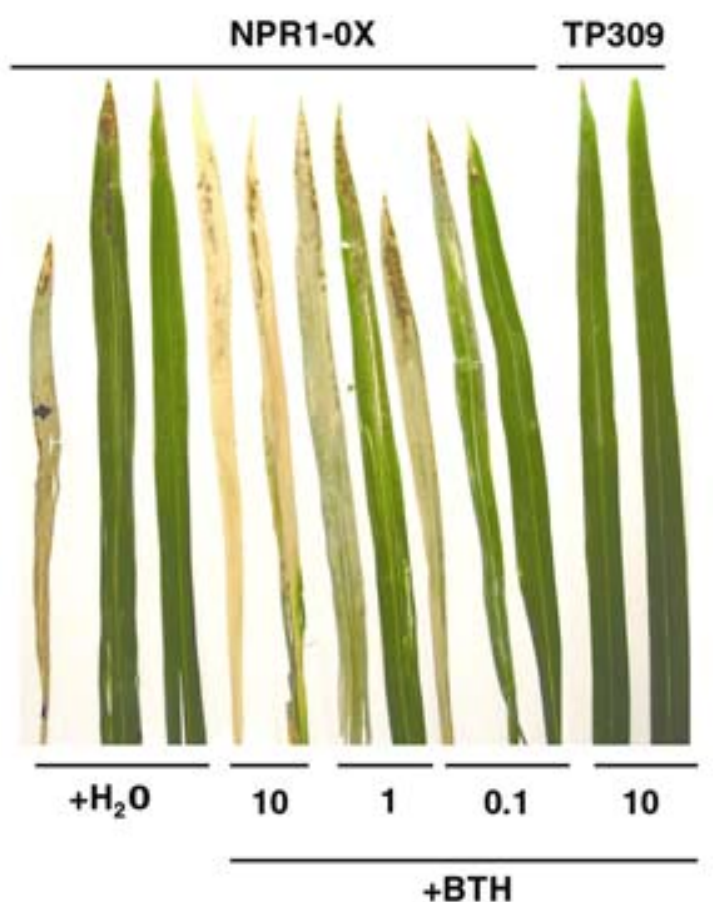

B

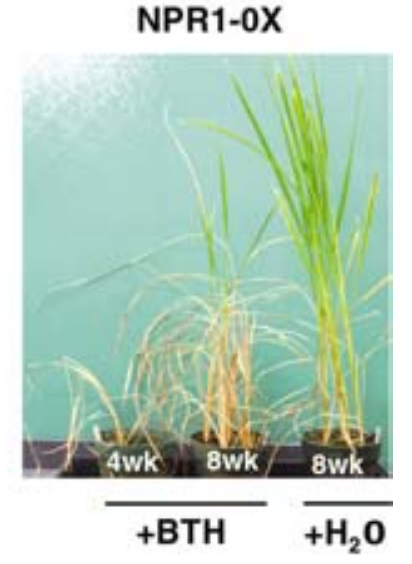

C

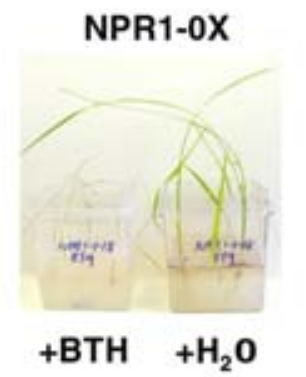

Fig. 2. Development of the lesion-mimic/cell death phenotype in NPR1-OX plants after treatment with increasing concentrations of benzo(1,2,3)-thiadiazole-7carbothioc acid (BTH) at different plant developmental stages. A, Leaves from NPR1-OX and control (TP309) plants grown in growth chambers. Plants were sprayed with water or BTH (in concentrations ranging from 0.1 to $10 \mathrm{mM}$ ). Mature leaves show chlorosis and death while young leaves develop lesions. BTHpotentiated symptoms are dose dependent. Pictures were taken 4 weeks posttreatment. B, BTH triggers death in 4-week-old as well as 8-week-old plants and C, in 2-week-old NPR1-OX plants grown under sterile conditions on synthetic growth medium. 
leaves and mature leaves died prematurely. In young (2 weeks old) NPR1-OX plants, chlorosis and enhanced senescence symptoms predominated. Lesions were visible only once plants reached approximately 3 weeks of age (Fig. 2B). Young plants developed similar LMD phenotypes when grown in soil or on synthetic media under sterile culture conditions (Fig. 2C). These results indicate that the LMD phenotype is triggered initially by the growth environment, in a development-independent manner. BTH potentiates the phenotype but its trigger requires an additional environmental factor because water-treated NPR1-OX plants also developed lesions and death.

\section{Independently derived NPR1-OX lines display lesions and death heritably.}

The experiments described above were performed only on NPR1-OX line \#1; therefore, the LMD phenotype could simply be an effect of insertion site mutagenesis by the (At)NPRl transgene or another nonlinked mutagenic event. If lesions and death occur as a result of $(A t) N P R l$ overexpression then the presence of the $(A t) N P R l$ transgene should correlate with the phenotype in independently derived NPR1-OX lines. Therefore, third generation (T2) transgenic NPR1-OX plants from five independently transformed lines (lines 1, 2, 6, 9, and 20) were treated with BTH and scored for the development of

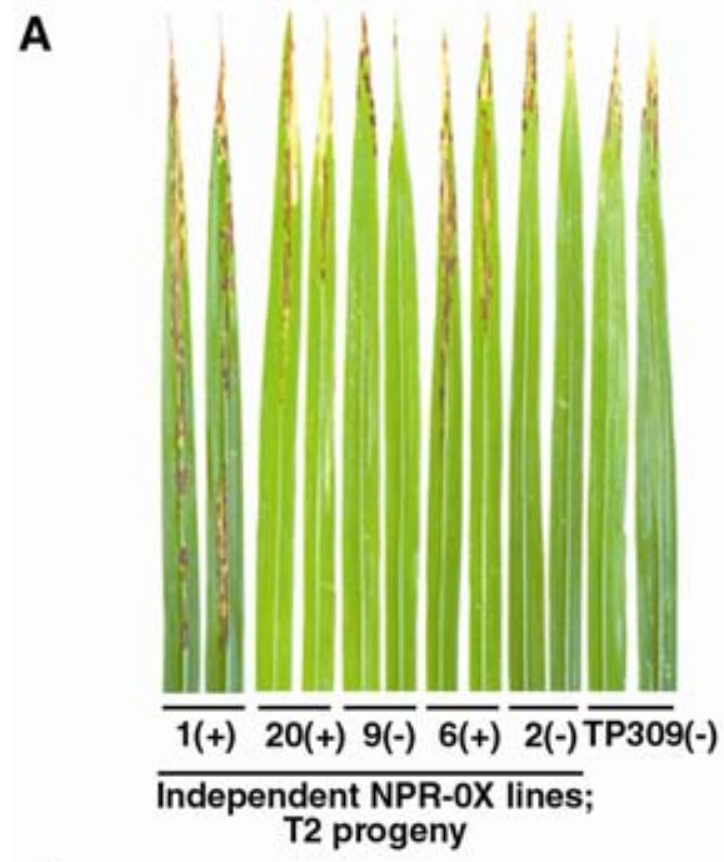

B

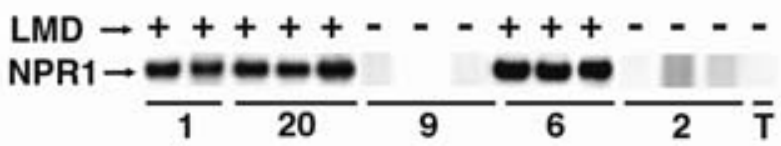

Fig. 3. Analysis of lesion development in third-generation NPR1-OX plants and detection of the (At)NPR1 transgene. A, Representative leaves of T2 generation plants from five independently transformed NPR1-OX lines; the plants for lines 2 and 9 are offspring from a T1 parent that lacked (At)NPR1. B, DNA was extracted from individual T2 plants and the (At)NPR1 gene amplified by polymerase chain reaction from independent lines $1,2,6,9$, and $20 . \mathrm{T}$ indicates the transformation recipient cultivar TP309; + indicates presence of lesions and death; - indicates absence of lesions and death. Six-week-old plants were treated with benzo(1,2,3)thiadiazole-7-carbothioc acid at $10 \mathrm{mM}$ and plants were scored 4 weeks posttreatment. Leaf picture was taken 2 weeks posttreatment.

the LMD phenotype. Lesions developed in the leaves of all T2 progeny that contained the (At)NPRl transgene and did not occur in $\mathrm{T} 2$ progeny that lacked the transgene (Fig. 3A). The presence of the $(A t) N P R l$ transgene in the T2 plants was determined by polymerase chain reaction (PCR) analysis using transgene specific primers as indicated below (Fig. 3B). Lines 1 and 6 developed particularly large lesions. It has been demonstrated previously that these two lines displayed higher resistance to $X$. oryzae pv. oryzae than other lines and strong (At)NPRl expression, suggesting that the LMD phenotype was correlated with enhanced resistance (Chern et al. 2001). The LMD phenotype was apparent in third-generation NPR1-OX plants with no apparent decrease in symptom development; therefore, these observations indicate that the phenotype is stable and heritable.

\section{Hydrogen peroxide $\left(\mathrm{H}_{2} \mathrm{O}_{2}\right)$ accumulates around lesions in NPR1-OX plants.}

The occurrence of lesions and cell death has been described for many mutants identified in screens for altered pathogen resistance. The accumulation of reactive oxygen species (ROS), such as $\mathrm{H}_{2} \mathrm{O}_{2}$ or $\mathrm{O}_{2}^{-}$, also is observed in the majority of these mutants (Lorrain et al. 2003). Therefore, $\mathrm{O}_{2}^{-}$and $\mathrm{H}_{2} \mathrm{O}_{2}$ accumulation was evaluated in NPR1-OX and TP309 plants. Young leaves (no visible lesions) or mature leaves (with lesions) were harvested from 6- or 8-week-old plants, approximately 1 week post- BTH $(10 \mathrm{mM})$ or water treatment. Superoxide accumulation was measured, at a gross level, by infiltrating leaves with nitro blue tetrazolium and observing the formation of a blue precipitate. The BTH-treated leaves of both NPR1OX and TP309 plants accumulated slightly elevated $\mathrm{O}_{2}^{-}$when compared with the water-treated leaves. However, there were no obvious differences in $\mathrm{O}_{2}^{-}$staining between NPR1-OX and TP309 plants. In a separate experiment, leaves also were harvested from water- or BTH-treated plants 4,24 , and $48 \mathrm{~h}$ after treatment in young leaves not yet displaying lesions. Even at these earlier times after treatment, no differential accumulation of superoxide was observed in NPR1-OX plants (data not shown). These data suggest that, at the times surveyed, there were not distinct differences in superoxide accumulation. However to definitively exclude a role for $\mathrm{O}_{2}^{-}$in development of the LMD phenotype, additional experiments, including measuring the exact activities of enzymes involved in superoxide metabolism in symptomatic leaf tissue, would also need to be performed.

Because $\mathrm{O}_{2}^{-}$is predicted to accumulate early in a stress response, it also is possible that differential $\mathrm{O}_{2}^{-}$accumulation

TP309

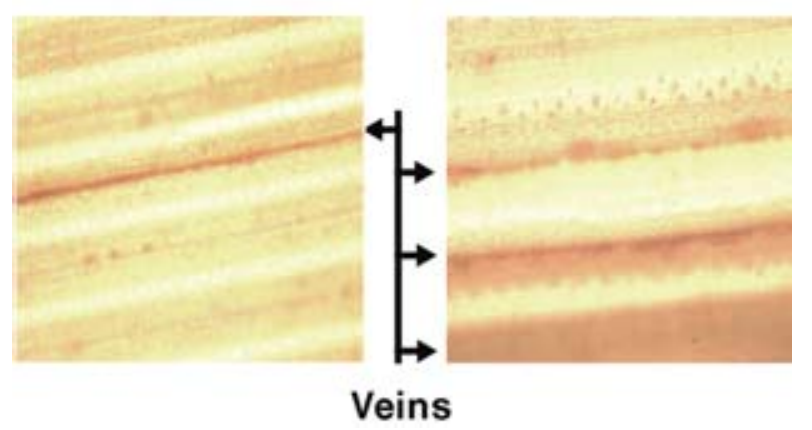

Fig. 4. Detection of $\mathrm{H}_{2} \mathrm{O}_{2}$ accumulation in NPR1-OX leaf tissue. Leaf sections adjacent to visible lesions from TP309 and NPR1-OX plants were harvested for analysis. Leaves were infiltrated with diaminobenzidine. Accumulation of $\mathrm{H}_{2} \mathrm{O}_{2}$ is indicated by the dark red precipitate staining the rice veins (indicated by arrows). Leaves were visualized using a light microscope at $\times 200$ magnification. 
was not observed in these plants because the $\mathrm{O}_{2}^{-}$was converted by superoxide dismutase (SOD) to form $\mathrm{H}_{2} \mathrm{O}_{2}$ prior to collection of the tissue. To detect $\mathrm{H}_{2} \mathrm{O}_{2}$ accumulation, leaves were infiltrated with 3,3'-diaminobenzidine (DAB) and the presence of a red-brown precipitate was monitored. Leaf tissue was collected from 6-week-old plants, not yet displaying lesions, at 4,24 , or $48 \mathrm{~h}$ after $\mathrm{BTH}$ or water treatment. In these samples, no accumulation of $\mathrm{H}_{2} \mathrm{O}_{2}$ was observed. Leaves from 6-week-old NPR1-OX plants, displaying lesions, were harvested along with leaves of similar developmental stages from TP309 control plants. In NPR1-OX leaves, the areas adjacent to visible lesions contained an increased number of veins displaying accumulation of a red-brown pigment (Fig. 4). These results indicate that $\mathrm{H}_{2} \mathrm{O}_{2}$ accumulates, prior to lesion expansion, in healthy tissue adjacent to visible lesions.

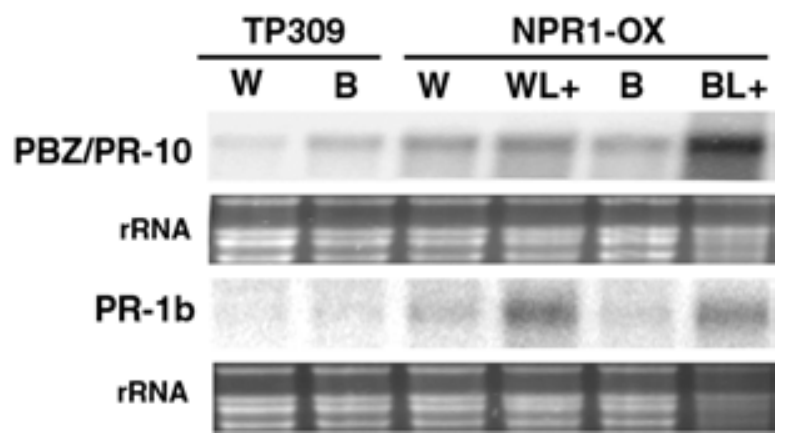

Fig. 5. Expression levels of the rice defense-associated genes $P B Z / P R-10$ and $P R-1 b$ in NPR1-OX plants. RNA was extracted from rice leaves of 6week-old plants, 1 week posttreatment. $\mathrm{W}=$ water-treated, or $\mathrm{B}=$ benzo $(1,2,3)$-thiadiazole-7-carbothioc acid-treated $(10 \mathrm{mM}), \mathrm{L}+=$ leaves displaying lesions. Leaves from NPR1-OX plants displaying lesions have elevated expression of both $P R-10$ and $P R-1 b$. Ethidium bromide staining of the rRNA in the respective RNA gels is shown as a gage of loading equivalency.
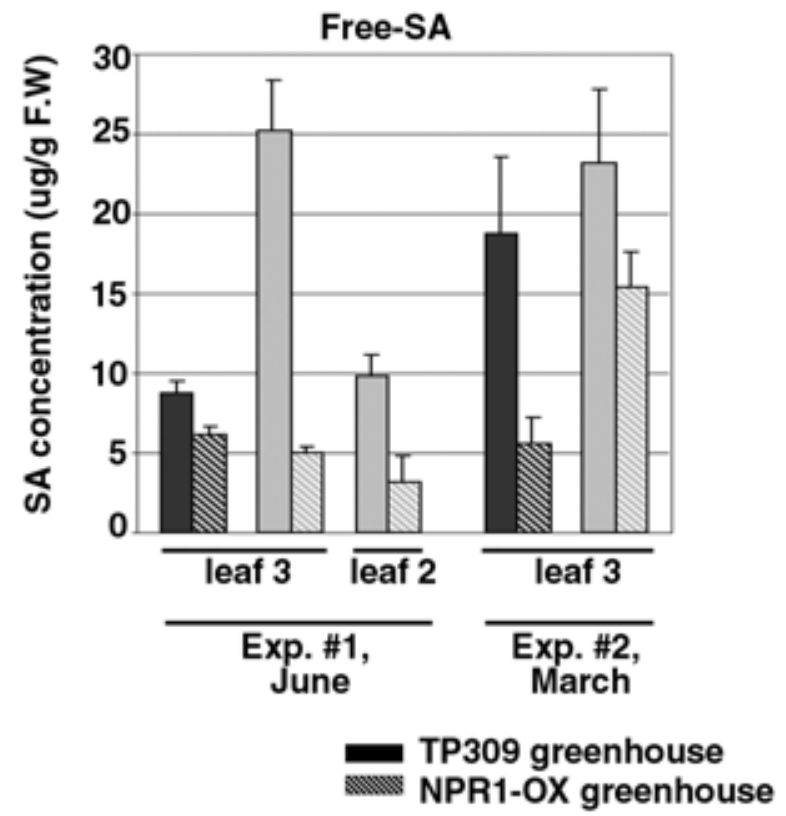

NPR1-OX leaf tissue, with visible lesions, displays increased expression

of the rice PR-like genes $P R-1 b$ and $P B Z / P R-10$.

PR gene expression is up-regulated concomitantly with enhanced resistance in Arabidopsis (Ward et al. 1991). Although no consistent correlations exist between the increased expression of PR-like genes and rice defense responses, studies of the rice lesion-mimic mutants, $s p l$ and $c d r$, show that expression of the rice PR-like genes $P R-1$ and $P B Z / P R-10$ correlates with necrotic lesion development (Takahashi et al. 1999; Yin et al. 2000). In Arabidopsis, overexpressing (At)NPRl PR genes are not constitutively expressed. To test whether or not PR-like genes were constitutively expressed in NPR1-OX rice, plants were grown in the greenhouse for 5 weeks and transferred to the growth chamber for an additional week. Plants were treated with BTH or water, and leaves with and without lesions were harvested 7 days later. The expression patterns of $P R-1 b$ and PBZ/PR-10 were analyzed by Northern blots. Rice plants overexpressing (At)NPRl had slightly elevated levels of $P R-1 b$ and PBZ/PR-10 when compared with the TP309 control, regardless of the treatment (Fig. 5). The largest difference in expression was observed between leaves from NPR1-OX plants with and without visible lesions. $P R-1 b$ transcript abundance was increased in leaves that contained lesions, regardless of the chemical treatment. PBZ/PR-10 transcript levels were less elevated in water-treated plants showing lesions but strongly elevated in BTH-treated plants showing lesions. Northern blots also were performed on RNA isolated from BTH- and watertreated NPR1-OX plants 4, 46, and $98 \mathrm{~h}$ posttreatment. At these times, leaves had not yet developed necrotic lesions. Induction of $P B Z / P R-10$ transcription was not observed in these Northern blots and the basal level of $P B Z / P R-10$ expression was very low (data not shown). The Northern blot data indicate that, as with other rice lesion-mimic mutants, the LMD phenotype in NPR1OX plants is correlated with enhanced PR-like gene expression. In addition, as is the case for Arabidopsis (At)NPRI overexpressing plants, rice PR-like genes are not prematurely expressed in the absence of a SAR stimulus.

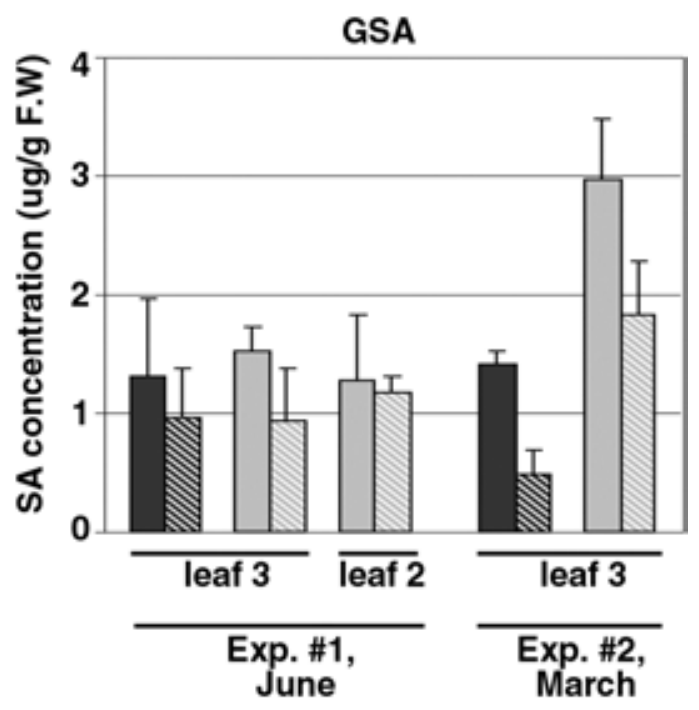

TP309 growth chamber
NPR1-OX growth chamber

Fig. 6. Accumulation of salicylic acid (SA) in NPR1-OX plants grown in two environments. Leaves were harvested from 3-week-old TP309 or NPR1-OX plants grown in the greenhouse or growth chamber at two different times of the year. Two to three replicate samples per cultivar (approximately 15 plants per cultivar for each growth environment) were analyzed by high-performance liquid chromatography to determine both free SA and glucose-conjugated SA (GSA) content. The graphs show the means and standard deviations for the sample replicates. NPR1-OX plants accumulated less SA than control (TP309) plants in both environments but accumulated similar amounts of GSA. 
Overexpression of $(A t) N P R 1$ correlates

with reduced $S A$ accumulation in rice leaves.

Accumulation of $\mathrm{SA}$ is intimately linked to (At)NPRlmediated systemic resistance in Arabidopsis and tobacco (Delaney et al. 1994; Ryals et al. 1996). When (At)NPRl was overexpressed in Arabidopsis using its endogenous promoter, plants demonstrated higher sensitivity to treatment with SA analogs but showed no alterations in endogenous SA levels (Friedrich et al. 2001). Therefore, rice overexpressing (At)NPRl was predicted to behave in a similar manner. To test this hypothesis, leaves 2 and 3 (Century et al. 1999) were harvested from multiple, 3-week-old NPR1-OX and TP309 plants, grown continuously in either the greenhouse or growth chamber. These experimental parameters were chosen for the following reasons. First, using plants of this age and size allowed SA measurements in the greatest possible number of plants practical in growth-chamber conditions. Second, the LMD phenotype could be initiated in 3-week-old plants; therefore. changes in SA levels, related to LMD development, also should have been observable. Third, several LMD symptoms developed first in mature leaves (leaves 2 and 3) of rice plants; therefore, these leaves were the most likely tissues to display SA differences. Finally, this sampling scheme also was designed so that the measurements made in this study could be compared with similar measurements made of rice leaf SA in the few other studies where it has been tested (Chen et al. 1997; Silverman et al. 1995). Two independent experiments were performed, one carried out in March and another in June. The concentration of free SA and glucosylated SA (GSA) in leaf tissue was determined using high-performance liquid chromatography (HPLC) (Fig. 6).

In the June experiment, greenhouse-grown TP309 plants had average levels of free SA that were slightly higher than those measured in NPR1-OX plants. Interestingly, growth chamber-grown TP309 plants had an over fivefold increase in SA compared with NPR1-OX growth chamber-grown plants and a threefold increase in SA compared with the corresponding greenhouse-grown TP309 plants. The levels of free SA in NPR1-OX plants were similar in each growth environment. In June, free-SA levels also were measured for leaf 2 of growth chamber-grown TP309 and NPR1-OX plants. The basal SA levels were lower in leaf 2 than leaf 3 , as has been reported for other rice cultivars (Chen et al. 1997). The average abundance of free SA in leaf 2 also was reduced in NPR1-OX plants compared with TP309 plants, suggesting that the SA reduction in NPR1-OX plants occurred regardless of leaf age.

When a second experiment was carried out in March under late-winter light conditions, greenhouse-grown TP309 accumulated higher levels of free SA than in the June experiment. Greenhouse-grown NPR1-OX plants again had low levels of SA, similar to those observed in the March experiment. Although the accumulation of SA in greenhouse-grown wildtype (TP309) plants in these two experiments was not identical, effects of light on SA accumulation might explain these results. The ability of light to modulate SA accumulation has been observed previously in Arabidopsis (Genoud et al. 2002).
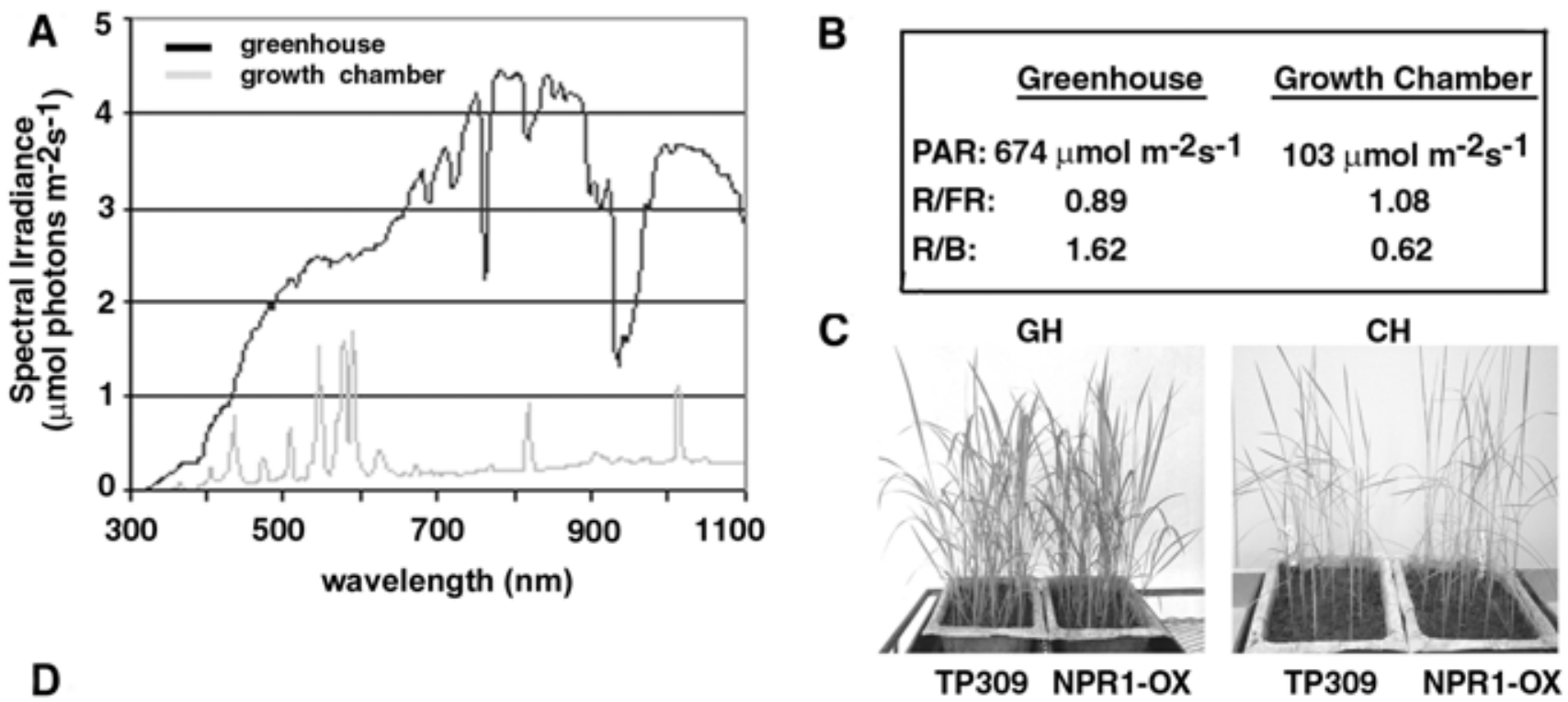

D
\begin{tabular}{|c|c|c|c|c|c|}
\hline Cultivar & Height $(\mathrm{cm})$ & F.W. (Aerial) (g) & Tiller \# & Leaf width $(\mathrm{mm})$ & $\mathrm{N}$ \\
\hline TP309-GH & $85.8+/-3.6$ & $22.72+/-5.20$ & $5+/-1$ & $12.2+/-0.7$ & 14 \\
\hline TP309-CH & $94.6+/-12.0$ & $5.99+/-2.28$ & $1+/-0$ & $10.6+/-1.5$ & 14 \\
\hline NPR1-OX-GH & $84.9+/-5.3$ & $20.28+/-6.59$ & $5+/-1$ & $12.1+/-0.7$ & 17 \\
\hline NPR1-OX-CH & $78.6+/-6.7$ & $2.59+/-0.80$ & $1+/-0$ & $7.6+/-1.4$ & 17 \\
\hline
\end{tabular}

Fig. 7. Spectral irradiation differences and plant morphology in two growing environments. A, Graph of the total light intensity at wavelengths from 300 to $1,100 \mathrm{~nm}$. Greenhouse measurements were made on a sunny April in midafternoon. Lights in the growth chamber are metal halide and incandescent. B, Photosynthetically active radiation (PAR) was calculated between 400 and $700 \mathrm{~nm}$. The red/far red/blue (R/FR/B) ratios are based on light intensity between wavelengths 650 and $680 \mathrm{~nm}(\mathrm{R}), 710$ and $740 \mathrm{~nm}(\mathrm{FR})$, and 430 and $470 \mathrm{~nm}$ (B). C, Approximately 30 plants per cultivar were grown either in the greenhouse $(\mathrm{GH})$ or growth chambers $(\mathrm{CH})$ for 3 weeks. D, At 8 weeks, plants were harvested and measured for height and fresh weight (F.W.) of the aerial portions of the plant, tiller number, and leaf width. 
In the March experiment, the SA levels in NPR1-OX growth chamber-grown plants were elevated compared with the levels observed in the June experiment. The temperature cycle and illumination parameters were constant in the growth chamber; therefore, this difference in SA levels was unexpected. However, the set of seed used in the two experiments was not identical. The LMD phenotype in the NPR1-OX plants (derived from NPR1-OX line 1, homozygous T2 parent 3) used for the March experiment developed slightly earlier than in the plants (derived from NPR1-OX line 1, homozygous T2 parent 18) used for the June experiments. Although the SA levels still were reduced in the March NPR1-OX plants, the extent of the difference may have been obscured by increases in SA from adjacent cells undergoing cell death (Alvarez 2000; Malamy et al. 1990; Metraux et al. 1990). Even in light of the differences between experiments, under all conditions the SA levels for NPR1-OX plants were notably lower than those observed for TP309 plants. The raw free-SA measurements (for leaf 3; $n=$ 23) were analyzed using a three-way analysis of variance (ANOVA) model comparing genotype (NPR1-OX or TP309), season (March or June), and growth conditions (greenhouse or growth chamber). From this analysis, the sample means for each group indicate significant variation as a result of genotype $(\mathrm{Pr}>F:<0.0001)$, as well as growth conditions $(\mathrm{Pr}$ $>F:<0.0001)$. Interestingly, there also was significant variation due to season $(\operatorname{Pr}>F$ : 0.0026$)$ and, when analyzed together, the statistics suggest a three-way interaction (although not two-way) among these variables $(\mathrm{Pr}>\mathrm{F}$ : 0.0003). Thus, at least as analyzed in this experiment, the NPR1-OX plants had reduced free-SA levels compared with the wild-type controls. GSA concentrations also were measured in these plants and were less than $2 \mu \mathrm{g} / \mathrm{g}$ of fresh weight for either NPR1-OX or TP309 rice for both experiments. In summary, (At)NPRl overexpression in rice is associated with reduced free-SA levels, consistent with an active role for (At)NPR1 in feedback inhibition of SA accumulation.

\section{Differences in light quality and plant morphology between greenhouse and growth chamber environments.}

NPR1-OX plants differ from wild-type controls in the development of lesions and death, ROS accumulation, PR gene expression, and SA content. These differences correlate with the overexpression of $(A t) N P R l$, but overexpression alone is not sufficient to trigger the responses; a second factor is required. The phenotypes appear when plants are grown in the growth chamber but do not appear when plants are grown in the greenhouse; therefore, the second factor is likely an input from the environment.

The largest differences between these two environments are in the abundance and quality of the light that plants perceive. The differences in the light regimens can vary substantially depending on the time of year experiments are performed. For example, the total daylight time in the greenhouse ranges from 8 to $15 \mathrm{~h}$. The full LMD phenotype could not be recapitulated in the greenhouse at any time of the year, regardless of the day length (data not shown). However, occasionally, when grown in the middle of winter, premature leaf death was observed in NPR1-OX plants. Other environmental factors, such as humidity, also may effect LMD development (Jambunathan et al. 2001). Humidity alone cannot be sufficient for the LMD response; though, because the greenhouse often had humidity levels that matched those in the growth chambers at times with abundant light, but the LMD phenotype was not triggered. These results suggest that overall light abundance may be important in triggering this response.

To determine the amount of light to which the NPR1-OX plants were subjected, the photosynthetically active radiation
(PAR; 400 to $700 \mathrm{~nm}$ ) and light intensity across the spectrum from 300 to $1,100 \mathrm{~nm}$ were measured in both growth environments. The differences in spectral intensity, measured in photon flux ( $\mu$ mol photons $\mathrm{m}^{-2} \mathrm{~s}^{-1}$ ), and PAR between the two environments are depicted in Figure 7A and B. The total PAR for plants grown in the greenhouse, in the spring, was six times higher than the PAR for plants grown in the growth chamber. In the spring, plants in the greenhouse received medium-high light and had roughly a 12-h light-and-dark cycle. The greenhouse light intensity was measured at its peak at one o'clock in the afternoon. The growth chambers were under a consistent light regiment, regardless of the time of the year; plants in it received low-intensity light and had a 12-h light-and-dark cycle. The growth chamber was equipped with only metal halide and incandescent lights. The total light intensity across wavelengths of light from 300 to 1,100 was 10 times higher in the greenhouse than in the growth chamber.

Differences also existed in the amount of light intensity at specific wavelengths. Some specific differences in these environments were the red (R: 650 to $680 \mathrm{~nm}$ )/far-red (FR: 710 to $740 \mathrm{~nm}$ ) ratios and red/blue (B: 430 to $470 \mathrm{~nm}$ ) ratios. These ratios often are altered in field conditions when plants are grown under tree canopies or crowded by other vegetation. In the greenhouse, the R/FR ratio was slightly reduced compared with the growth chamber, whereas the $\mathrm{R} / \mathrm{B}$ ratio was elevated in the greenhouse (Fig. 7B). These ratios indicate that the greenhouse had a greater relative proportion of far-red light compared with the growth chamber, and the growth chamber had a greater relative proportion of blue light than the greenhouse. Fluences for red, far-red, or blue light in the growth chamber were $<10$ $\mu \mathrm{mol} \mathrm{m} \mathrm{m}^{-2} \mathrm{~s}^{-1}$. In the greenhouse, the fluence levels were approximately $100 \mu \mathrm{mol} \mathrm{m} \mathrm{m}^{-2} \mathrm{~s}^{-2}$, for both red and far-red light, and $58 \mu \mathrm{mol} \mathrm{m} \mathrm{m}^{-2} \mathrm{~s}^{-2}$ for blue light. Therefore, the strong decrease in light intensity in these wavelengths in the growth chamber is apparent in these measurements.

Plants grown in the growth chamber morphologically resembled plants grown in shade conditions (where there is generally lower intensity far-red and red light, as well as a lower R/FR ratio). To quantitate the extent of these morphological differences, growth characteristics were measured in control and NPR1-OX plants grown in both environments for 8 weeks (Fig. 7C and D). Plants grown in greenhouse conditions had greater leaf and shoot biomass, an increased number of tillers, and slightly larger leaf widths than plants grown in the growth chamber. NPR1-OX plants had a slight decrease in shoot expansion and reduced biomass and leaf width when grown in a growth chamber compared with control (TP309) plants in the same environment. At 8 weeks of age, the LMD symptoms in NPR1-OX plants were beginning to be apparent in these conditions, as reflected by these data. Additional factors may trigger the LMD phenotype in NPR1-OX plants; however, based on the above observations of plant growth, light intensity may play a significant role.

\section{DISCUSSION}

In Arabidopsis, overexpression of (At)NPRl confers broadspectrum disease resistance but does not initiate unfavorable side-effects (Friedrich et al. 2001; Zhang et al. 1999). In rice, overexpression of $(A t) N P R l$ similarly enhances disease resistance to the bacterial pathogen $X$. oryzae pv. oryzae (Chern et al. 2001). In this study, we demonstrate that, unlike Arabidopsis, overexpression of $(A t) N P R l$ in rice is associated with detrimental side effects under particular growing conditions. NPR1-OX rice plants grown in controlled environment chambers (in general, lower light and higher humidity) develop an LMD phenotype. 
An alteration in the light regimen is postulated to be one factor initiating the collapse and death of NPR1-OX plants. In dicots, plant lesion-mimic phenotypes can develop after exposure to elevated or reduced light intensity. The Arabidopsis lsd lesion-mimic mutants provide examples of these effects. Lesion formation in $l s d l$ plants is triggered by high-intensity light, whereas the lesions in $l s d 5$ mutant plants are stimulated in low-intensity light environments (Dietrich et al. 1994). Light also plays an important role in the development of lesionmimics in cereals. Lesions in the rice $s p l$ mutants are triggered by long-day conditions, and the barley $l l s l$ mutant specifically requires high-intensity light, rather than a particular light quality, to induce lesions (Arase et al. 2000; Gray et al. 2002; Kiyosawa et al. 1970). Experiments in this study demonstrate that the lesion-mimic phenotype in NPR1-OX rice develops in plants grown under low-intensity light conditions (growth chambers). There are strong morphological changes observed in rice grown in growth chambers, and these differences are more pronounced in NPR1-OX plants. In future studies, it will be important to determine if any connections exist between signaling pathways controlling these morphologies and those regulating the LMD phenotype or the activity of (At)NPRl.

Interestingly, the lesion development in NPR1-OX plants also follows a developmentally programmed pattern. In NPR1OX plants, the cell death phenotype propagates from mature leaves to young leaves, and lesions occur in the rapidly dividing tissue of young leaves. Lesion formation is more prevalent in plants that are at least 3 weeks old. Therefore, plant developmental programs also contribute to the extent and timing of the LMD phenotype. In the Arabidopsis dlll and acd5 mutants, lesions also are programmed developmentally and appear in fully mature leaves only after plants have proceeded at least half way through their life cycle (Greenberg et al. 2000; Pilloff et al. 2002). Natural senescence programs could contribute to the developmental variance in symptoms, at least in NPR1-OX plants. Studies monitoring molecular markers of senescence, such as gene expression, indicate that SA enhances the production of senescence-associated genes transcripts. The influences of SA on senescence may work partly through the action of (At)NPRl because nprl-1 mutants resist the chlorosis and bleaching that are associated with leaf senescence longer than wild-type plants (Morris et al. 2000). In this study, an opposite effect is observed; overexpression of (At)NPRl seems to increase mature leaf senescence and chlorosis.

(At)NPR1 may affect multiple plant-signaling pathways; it is implicated in senescence as well as the SA-independent induced systemic resistance (ISR) pathway (Pieterse et al. 1998; Zhang et al. 1999). Recent studies also suggest that (At)NPR1 may modulate cross talk between the SA and jasmonic acid-mediated resistance pathways through an unknown function in the cytosol (Spoel et al. 2003). However, the primary function of (At)NPR1 is predicted to be regulation of PR genes via interaction with the TGA transcription factors. In Arabidopsis, a SAR stimulus is needed to trigger (At)NPR1-mediated regulation of gene expression, possibly one reason that detrimental effects of $(A t) N P R$ overexpression have not been observed previously. The LMD phenotype in NPR1-OX rice could be associated with precocious PR gene expression, as is the case with the Arabidopsis cpr mutants, and transgenic rice overexpressing rice $P R-2$ (a $\beta$-glucanase) (Clarke et al. 2000; Nishizawa et al. 2003). However, NPR1OX rice did not have a substantial increase in the expression of the rice $P R-1 b$ or $P B Z / P R-10$ genes in nonstimulated conditions. In the leaf tissue of NPR1-OX plants that displayed the LMD phenotype, the expression of these genes was greatly increased. The expression of $P B Z / P R-10$ has been shown to be induced in both probenazole- and BTH-treated rice leaves (Lee et al. 2001; McGee et al. 2001; Mido and Ihwata 1996). $P R-1 b$ is one of three isoforms of the rice basic $P R-1$ gene family that shows increased expression in the incompatible interactions of $X$. oryzae pv. oryzae and rice (Agrawal et al. 2000; M. Yoshikawa and M. Whalen, personal communication). Thus, the transcriptional elevation of $P R-1$ and $P B Z / P R$ 10 in rice is associated with lesion development and disease resistance. Both of these responses occur in NPR1-OX rice, but elevation of PR gene transcription is not constitutive; it is limited to leaves displaying visible lesions.

Multiple stimulus response pathways may contribute to LMD phenotype development in NPR1-OX rice but are not likely the LMD initiating factors. For many lesion-mimic mutants, lesions are triggered when the endogenous plant cell ROS levels are altered, and this also may be the case for NPR1-OX rice. Excess light alters the homeostasis of ROS in plants by tilting the life-or-death balance in plants toward death (Jabs 1999). For example, in $l s d l$ plants, the lesion phenotype is triggered by changes in the light regimen or treatment with BTH. The levels of superoxide $\left(\mathrm{O}_{2}^{-}\right)$are increased in $l s d l$ plants and this enhanced accumulation of $\mathrm{O}_{2}{ }^{-}$ is proposed to increase lesion spread (Jabs et al. 1996). Several species of Arabidopsis are long-day adapted and grow well under moderate to low-light conditions (PAR = approximately 50 to $100 \mu \mathrm{mol} \mathrm{m} \mathrm{m}^{-2} \mathrm{~s}^{-1}$. For these species high light is a stressinducing condition. Species of rice, on the other hand, are short-day-adapted plants that grow best under very high-light

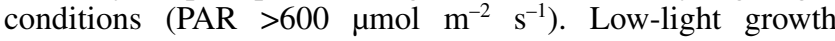
conditions may stress rice plants. Lesions in NPR1-OX plants spread, are affected by light quality and quantity, and the phenotypes appear similar; therefore, the accumulation of ROS was measured in NPR1-OX plants. The tissue surrounding developing lesions in NPR1-OX leaves accumulates $\mathrm{H}_{2} \mathrm{O}_{2}$, but accumulation of ROS was not observed elsewhere in the plant. Thus, low light abundance does not contribute to substantial enhancement of ROS levels systemically. It is possible that ROS levels are enhanced throughout the plant, but to a level that is not detectable using histochemistry. A systemic low-level increase, however, may be sufficient, over time, to push redox homeostasis out of balance and toward death.

SA can affect ROS levels in Arabidopsis by functioning in a feedback loop with $\mathrm{NO}$ and $\mathrm{H}_{2} \mathrm{O}_{2}$ (Alvarez 2000; Delledonne et al. 2001; Jabs 1999). In combination with ROS, SA also can initiate cell death in otherwise healthy Arabidopsis plants (Jabs 1999). SA metabolism appears to differ substantially between rice and Arabidopsis. Although Arabidopsis have constitutively low levels of free SA, rice has very high levels of free SA; for example, approximately $10 \mu \mathrm{g} / \mathrm{g}$ of fresh weight (FW) in the cultivar Taipei 309; in some cultivars, this value can approach $30 \mu \mathrm{g} / \mathrm{g} \mathrm{FW}$ (Silverman et al. 1995). The contribution of GSA to this total is negligible. Arabidopsis have very high GSA levels, suggesting that excess free SA is conjugated rapidly to glucose to help detoxify high-cytosolic SA levels, and to serve as a store for SA. Either high levels of free SA are not toxic to rice, or other methods are actively employed in rice to minimize the toxic effects of SA. Our studies indicate that SA levels are reduced in NPR1-OX rice plants, and that SA levels can alter substantially depending on the conditions in growing environments. This is the first observation of a decrease in SA associated with (At)NPRl overexpression. (At)NPRl overexpression has not been reported to affect SA accumulation in other plants; however, loss of $(A t) N P R l$, such as in the Arabidopsis niml-1 mutants, does allow greater accumulation of SA after pathogen infection (Delaney et al. 1995). In addition, (At)NPRI overexpression in Arabidopsis has been demonstrated to increase the sensitivity to SA-analogs, 
such as BTH, as well as other fungicides (Freidrich et al. 2001; Kohler et al. 2002). These experiments suggest that SA is required for (At)NPR1 activation but, in turn, (At)NPR1 may be involved in feedback regulation or detoxification of high levels of SA.

It is possible that the higher endogenous levels of SA in rice simply allow for easier detection of reduction in SA levels, or that (At)NPR1 simply interacts differently with rice proteins for regulation of SA levels. Alternatively, the ability to regulate SA levels may be an intrinsic property of (At)NPR1 and its homologs in other plant species, and its overexpression in plants that have different SA metabolisms will lead to unpredicted side effects. Preliminary analyses of rice plants overexpressing a rice (At)NPRl-homolog indicate that a similar LMD phenotype develops. The LMD occurs more strongly in these lines and is more easily initiated by environmental changes (M. S. Chern, H. Fitzgerald, and P. C. Ronald, unpublished data). Potato, like rice, has very high SA levels, and it will be interesting to see if a similar phenomenon occurs when overexpressing either (At)NPRl or its potato homolog.

The data presented in this study favor a model whereby (At)NPR1 senses SA levels and directly contributes to the feedback-inhibition of SA accumulation (Cao et al. 1997; Delaney et al. 1995). Recent studies indicate that one effect of SA accumulation is to help generate a reducing cytosolic environment that stimulates the depolymerization of (At)NPR1 oligomers into monomeric forms that can translocate into the nucleus and regulate gene expression (Mou et al. 2003). One simple explanation for the data presented in this study is that (At)NPR1 is sensitive to the high levels of SA in rice, possibly through SA affecting ROS levels and subsequently the oligomerization of (At)NPR1. Growing rice plants under particular environmental conditions alters the accumulation of free SA. In NPR1-OX plants, (At)NPR1 is sensitive to SA and may downregulate its accumulation in conditions that would otherwise favor its accrual. Sustained decreases in SA, in turn, also unbalance the plant redox status and result eventually in death.

Some important goals of agricultural genetic engineering, include creating crops that are durable to stresses, require fewer chemical inputs, and do not show unwanted agronomic effects. Transgenic expression of $(A t) N P R 1$ in multiple plant species with the aim of enhancing endogenous plant SAR responses has been proposed as one attractive method for reaching these goals. However, data in this study indicate that overexpressing $(A t) N P R l$ in rice leads to pleiotropic effects that may impede its usefulness in particular growing conditions. A limitation to this study is that $(A t) N P R l$ is expressed from a strong constitutive promoter in a heterologous system. However, previous studies of overexpressing (At)NPRl in Arabidopsis with strong constitutive promoters, or with its own promoter, have not observed such effects (Freidrich et al. 2001; Zhang et al. 1999). Additional studies are still needed to determine whether or not this LMD phenotype will occur in other cereals, or if it is limited to plants with distinct SA metabolisms. Some crop species may not contain genes homologous to SAR components that can confer resistance; in these cases, heterologous expression may be the only transgenic option. Future studies to dissect the role $(A t) N P R l$ plays in disparate plant responses will help fine tune transgenic approaches for enhancing disease resistance through the manipulation of the SAR signaling pathway in plants.

\section{MATERIALS AND METHODS}

Plant materials and growth conditions.

The rice japonica cultivar Taipei 309 (TP309) was used as the recipient for Agrobacteria-mediated transformation of the
Arabidopsis NPRl gene. Construction of these lines has been described previously (Chern et al. 2001). Rice plants were grown in either greenhouse or growth-chamber conditions. In both environments, the plants were grown in autoclaved clay soil and fertilized three times throughout the growing cycle with ammonium sulfate. In the greenhouse, the photoperiod varied from 8 to $16 \mathrm{~h}$ and temperature ranged from 20 to $35^{\circ} \mathrm{C}$, depending on the time of the year; PAR for a sunny day was approximately $670 \mu \mathrm{mol}$ photon $\mathrm{m}^{-2} \mathrm{~s}^{-1}$. Relative humidity in the greenhouse was $>80 \%$. The growth-chamber conditions were controlled and set for a 12-h photoperiod with a relative humidity of $85 \%$ in the day and $95 \%$ at night and a temperature of $28^{\circ} \mathrm{C}$. The chamber was equipped with metal halide and incandescent lights providing a PAR of 103 $\mu \mathrm{mol}$ photons $\mathrm{m}^{-2} \mathrm{~s}^{-1}$. For sterile growth conditions, rice seed were surface sterilized with $10 \%$ bleach, then rinsed three times with ethanol. Seed were germinated and grown on Murashige-Skoog agar medium supplemented with $3 \%$ sucrose in magenta boxes. Rice plants were grown generally to 6 weeks of age in the greenhouse and then transferred to a growth chamber 4 to 6 days prior to infection with $X$. oryzae pv. oryzae or chemical treatment. Due to agricultural restrictions in California, rice can be infected with this pathogen only in controlled environments. The leaves of the rice were sprayed with chemicals, then infected with $X$. oryzae pv. oryzae 2 to 4 days after treatment to allow for the up-regulation of SAR before infection.

\section{Plant chemical treatments and light measurements.}

The leaves of rice plants of various ages were sprayed until runoff with a solution of BTH in concentrations ranging from 0.01 to $50 \mathrm{mM}$. The BTH solutions were made from suspensions of BTH supplied as the granule form of Actigard 50WG (50\% active ingredient) in water with $0.02 \%$ Tween-20. Actigard was provided as a kind gift from Novartis. Water containing $0.02 \%$ Tween-20 was sprayed on plants as a control. Total light abundance and quality were monitored using a LiCor 1800 spectroradiometer. PAR reflects the total light intensity between 400 and $700 \mathrm{~nm}$. Light ratios are based on measurements as follows: red $(650$ to $680 \mathrm{~nm})$, far red (710 to $740 \mathrm{~nm})$ and blue (430 to $-470 \mathrm{~nm})$.

\section{DNA and RNA extraction, PCR and Northern blotting.}

Genomic DNA was extracted from rice leaves using a previously described protocol (Dellaporta et al. 1984). The (At)NPRl transgene was amplified by PCR using the (At)NPRl-specific primer Npr1-7 as described (Chern et al. 2001 ) and the maize ubiquitin promoter-specific primer Ubi-1 (5' TGATATACTTGGATGATGGCA 3'). Genomic RNA was isolated from leaves ground with a mortar and pestle under liquid nitrogen. RNA was extracted from the homogenate using the Trizol reagent (Life Technologies, Gaithersburg, MD, U.S.A.) and a modified protocol as follows: for each gram of tissue ground, $3 \mathrm{ml}$ of reagent was used and, following extraction, the RNA was precipitated with $2 \mathrm{M} \mathrm{LiCl}$, resuspended, and precipitated again using ethanol (Sambrook et al. 1989). For each Northern blot, between 10 and $20 \mu \mathrm{g}$ of total RNA per sample was separated by electrophoresis using a $1.2 \%$ formaldehyde gel. The RNA was transferred to a Hybond $\mathrm{N}+$ membrane (Amersham, Buckingham, U.K.) according to the manufacturer's instructions, UV-crosslinked, and then baked for $1 \mathrm{~h}$ at $80^{\circ} \mathrm{C}$. The membranes were probed with DNA probes specific to either the $P B Z / P R-10$ or $P R-1 b$ genes. The $P B Z / P R-10$ DNA probe (GenBank accession number E12488) was amplified from rice genomic DNA preparations using the primers PBZ1-5 (5' CATGCTACTGCTCACCTTTGA 3') and PBZ1-6 (5' TCACTCTAGGTGGGATATACT 3'), which gen- 
erates an amplicon that includes at least $50 \mathrm{bp}$ of both the $5^{\prime}$ and $3^{\prime}$ untranslated regions. PCR was performed using standard conditions with a temperature cycle as follows: $94^{\circ} \mathrm{C}(2$ min); 40 cycles of $94^{\circ} \mathrm{C}(1 \mathrm{~min}), 55^{\circ} \mathrm{C}(1 \mathrm{~min})$, and $72^{\circ} \mathrm{C}(1$ $\mathrm{min})$; and $72^{\circ} \mathrm{C}(10 \mathrm{~min})$. A plasmid containing a $P R-1$ amplicon that hybridizes specifically to the $P R-1 b$ isoform (GenBank accession number U89895) was provided by $\mathrm{M}$. Yoshikawa and M. Whalen. The $P R I b$-specific $P R-1$ fragment amplified using the universal M13 forward and reverse primers and the following temperature cycles: $94^{\circ} \mathrm{C}(2 \mathrm{~min})$; 35 cycles of $94^{\circ} \mathrm{C}(30 \mathrm{~s}), 55^{\circ} \mathrm{C}(30 \mathrm{~s})$, and $72^{\circ} \mathrm{C}(30 \mathrm{~s})$; and $72^{\circ} \mathrm{C}(10 \mathrm{~min})$. DNA fragments amplified by PCR were purified from agarose gels using a spin-filter (Gene Clean and Concentrator; Zymo Research, Orange, CA, U.S.A.). Approximately 50 to $100 \mathrm{ng}$ of each probe were labeled with $\alpha-{ }^{32} \mathrm{P}$ dCTP using Ready-To-Go labeling beads (Amersham Biosciences, Piscataway, NJ, U.S.A.). Membranes were incubated for 2 to $4 \mathrm{~h}$ in prehybridization solution $(5 \times \operatorname{SSPE}[1 \times$ SSPE is $0.18 \mathrm{M} \mathrm{NaCl}, 10 \mathrm{mM} \mathrm{NaPO}_{4}$, and $1 \mathrm{mM}$ EDTA, ph 7.7], $5 \times$ Denharts, $0.5 \% \mathrm{wt} / \mathrm{vol}$ sodium dodecyl sulfate [SDS], $50 \%$ formamide, $10 \% \mathrm{wt} / \mathrm{vol}$ dextran sulfate), then hybridized overnight after addition of the ${ }^{32} \mathrm{P}$-labeled probes. After hybridization, membranes were washed twice at room temperature (RT) with solution 1 ( $2 \times \mathrm{SSPE}, 0.1 \% \mathrm{SDS})$, washed once at $65^{\circ} \mathrm{C}$ with solution $2(1 \times \mathrm{SSPE}, 0.1 \%$ SDS $)$, and washed once at RT with solution 3 (0.1\% SSPE, 0.2\% SDS). Phosphoimager screens then were exposed to the membranes for 6 to $14 \mathrm{~h}$ and the image captured using the Storm Imaging System (Molecular Dynamics, Sunnyvale, CA, U.S.A.)

\section{Histochemical detection of $\mathrm{H}_{2} \mathrm{O}_{2}$ and $\mathrm{O}_{2}^{-}$.}

Leaf sections of approximately $5 \mathrm{~cm}$ in length were excised from either TP309 or NPR1-OX plants of different ages and with chemical treatments, as indicated in the Results section. For detection of $\mathrm{H}_{2} \mathrm{O}_{2}$, leaf sections were placed in water with $0.01 \%$ Triton-X-100 and DAB at $1 \mathrm{mg} / \mathrm{ml}$ (SigmaAldrich, St. Louis). This solution was infiltrated with low vacuum pressure for $30 \mathrm{~min}$ and the leaves were incubated overnight at RT. DAB polymerizes in the presence of $\mathrm{H}_{2} \mathrm{O}_{2}$ to form a brownish-red precipitate that can be visualized. To detect $\mathrm{O}_{2}^{-}$accumulation, a solution containing $10 \mathrm{mM}$ potassium phosphate buffer ( $\mathrm{pH} 7.8)$ and $10 \mathrm{mM}$ sodium azide was infiltrated into leaf sections by vacuum pressure for 10 min. The addition of sodium azide makes the detection specific for $\mathrm{O}_{2}{ }^{-}$rather than $\mathrm{H}_{2} \mathrm{O}_{2}$. After the infiltration, the solution was replaced with new phosphate buffer containing $0.1 \%$ nitro blue tetrazolium (NBT), infiltrated for another 15 min with vacuum pressure, and allowed to incubate overnight at RT. When NBT interacts with $\mathrm{O}_{2}^{-}$, it is reduced and a blue precipitate forms at the site of contact and is visible in leaves cleared of chlorophyll. After incubation with either DAB or NBT, leaves were fixed and cleared in alcoholic lacto-phenol (2:1:1, 95\% ethanol:lactic acid:phenol) at $65^{\circ} \mathrm{C}$ for $30 \mathrm{~min}$, rinsed with $50 \%$ ethanol, and then rinsed with water. To visualize staining, whole leaf sections were incubated in $70 \%$ glycerol and mounted on slides. Microscopy was performed using a light microscope (Leica, Heielberg Germany).

\section{SA measurements}

Free SA and GSA levels from leaf tissue were analyzed from 3 -week-old rice plants. Plants were grown in soil in either greenhouse or growth-chamber environments as described above. For each sample, the second and third leaves were harvested from between 9 and 18 plants, depending on the cultivar. All leaves for each sample were randomly split into three equal groups (of fresh tissue weight between 20 and 200 $\mathrm{mg}$ ) and ground under liquid nitrogen. Triplicates of each sample were extracted and measured for SA independently. The samples were extracted with slight modification to the standard SA extraction procedures (Bowling et al. 1994). Briefly, O-anisic acid was added to the culture as an internal standard of recovery. Average recovery rates were approximately $70 \%$. Extracts were injected into an HPLC machine (Agilent 1100; Agilent Technologies, Palo Alto, CA, U.S.A.) with a Novapak $\mathrm{C} 18$ column at a flow rate of $1 \mathrm{ml} / \mathrm{min}$ at $25^{\circ} \mathrm{C}$. The isocratic mobile phase was $23 \%$ methanol and $77 \%$ $20 \mathrm{mM}$ sodium acetate, $\mathrm{pH}$ 5.5. SA was detected fluorometrically using excitation and emission wavelengths of 296 and $405 \mathrm{~nm}$, respectively. Statistical analysis on the raw, free SA measurements for leaf 3 was performed using SAS software (SAS Institute, Inc., Cary, NC, U.S.A.). The Shapiro-Wilk test for normality indicated that the data were suitable for analysis using a three-way ANOVA comparing group means.

\section{ACKNOWLEDGMENTS}

We thank N. Willits for performing statistical analysis of the SA measurements; M. Whalen and M. Yoshikawa for sharing unpublished information about $P R-1 b$; L. Friedrich at Syngenta for the kind gift of BTH; M. Campbell, S. Burdman, T. Richter, and C. Dardick for the critical reading of this manuscript; and the entire Ronald lab for valuable discussion and advice on this project.

\section{LITERATURE CITED}

Agrawal, G. K., Rakwal, R., and Jwa, N. S. 2000. Rice (Oryza sativa L.) OsPR $1 b$ gene is phytohormonally regulated in close interaction with light signals. Biochem Biophys. Res Commun. 278:290-298.

Alvarez, M. 2000. Salicylic acid in the machinery of hypersensitive cell death and disease resistance. Plant Mol. Biol. 44:429-442.

Arase, S., Fujita, K., Uehara, T., Honda, Y., and Isota, J. 2000. Lightenhanced resistance to Magnaporthe grisea infection in the rice Sekiguchi lesion mutants. J. Phytopathol. 148:197-203.

Bowling, S. A., Guo, A., Cao, H., Gordon, A. S., Klessig, D. F., and Dong, X. 1994. A mutation in Arabidopsis that leads to constitutive expression of systemic acquired resistance. Plant Cell 6:1845-1857.

Buschges, R., Hollricher, K., Panstruga, R., Simons, G., Wolter, M., Frijters, A., van Daelen, R., van der Lee, T., Diergaarde, P., Groenendijk, J., Topsch, S., Vos, P., Salamini, F., and Schulze-Lefert, P. 1997. The barley Mlo gene: a novel control element of plant pathogen resistance. Cell 88:695-705.

Cao, H., Bowling, S. A., Gordon, S. A., and Dong, X. 1994. Characterization of an Arabidopsis mutant that is nonresponsive to inducers of systemic acquired resistance. Plant Cell 6:1583-1592.

Cao, H., Glazebrook, J., Clarke, J. D., Volko, S., and Dong, X. 1997. The Arabidopsis NPRl gene that controls systemic acquired resistance encodes a novel protein containing ankyrin repeats. Cell 88:57-63.

Cao, H., Li, X., and Dong, X. 1998. Generation of broad-spectrum disease resistance by overexpression of an essential regulatory gene in systemic acquired resistance. Proc. Natl. Acad. Sci. U.S.A. 11:6531-6536.

Century, K. S., Lagman, R. A., Adkisson, M., Morlan, J., Tobias, R., Schwartz, K., Smith, A., Lov, J., Ronald, P. C., and Whalen, M. C. 1999. Short communication: developmental control of Xa21-mediated disease resistance in rice. Plant J. 20:231-236.

Chen, Z., Iye, S., Caplan, A., Klessig, D., and Fan, B. 1997. Differential accumulation of salicylic acid and salicylic acid-sensitive catalase in different rice tissues. Plant Physiol. 114:193-201.

Chern, M. S., Fitzgerald, H. A., Yadav, R. C., Canlas, P. E., Dong, X., and Ronald, P. C. 2001. Evidence for a disease-resistance pathway in rice similar to the NPR1-mediated signaling pathway in Arabidopsis. Plant J. 27:101-113.

Clarke, J. D., Volko, S. M., Ledford, H., Ausubel, F. M., and Dong, X. 2000. Roles of salicylic acid, jasmonic acid, and ethylene in cprinduced resistance in Arabidopsis. Plant Cell 12:2175-2190.

Dietrich, R. A., Delaney T. P., Uknes, S. J., Ward, E. R., Ryals, J. A., and Dangl, J. L. 1994. Arabidopsis mutants simulating disease resistance response. Cell 77:565-577.

Delaney, T. P., Friedrich, L., and Ryals, J. A. 1995. Arabidopsis signal transduction mutant defective in chemically and biologically induced disease resistance. Proc. Natl. Acad. Sci. U.S.A. 92:6602-6606.

Delaney, T. P., Uknes, S., Vernooij, B., Friedrick, L., Weymann, K., Negrotto, D., Gaffney, T., Gut-Rella, M., Kessman, H., Ward, E., and 
Ryals, J. 1994. A central role of salicylic acid in plant disease resistance. Science 266:1247-1250.

Dellaporta, S. L., Wood, J., and Hicks, J. B. 1984. Maize DNA miniprep. Pages 36-37 in: Molecular Biology of Plants: A Laboratory Course Manual. R. Maimberg, ed. Cold Spring Harbor Laboratory, Cold Spring Harbor, NY, U.S.A.

Delledonne, M., Zeier, J., Marocco, A., and Lamb, C. 2001. Signal interactions between nitric oxide and reactive oxygen intermediates in the plant hypersensitive disease resistance response. Proc. Natl. Acad. Sci. U.S.A. 98:13454-13459.

Fan, W., and Dong, X. 2002. In vivo interaction between NPR1 and transcription factor TGA2 leads to salicylic acid-mediated gene activation in Arabidopsis. Plant Cell 14:1377-1389.

Friedrich, L., Lawton, K., Dietrich, R., Willits, M., Cade, R., and Ryals, J. 2001. NIM1 overexpression in Arabidopsis potentiates plant disease resistance and results in enhanced effectiveness of fungicides. Mol. Plant-Microbe Interact. 9:1114-1124.

Friedrich, L., Lawton, K., Ruess, W., Masner, P, Speckner, N., Gut Rella M., Meier, B., Dinsher, S., Staub, T., Uknes, S., Metraux, J.-P., Kessman, H., and Ryals, J. 1996. A benzothiadiazole derivative induces systemic acquired resistance in tobacco. Plant J. 9:61-70.

Gaffney, T., Friedrich, L., Vernooij, B., Negrotto, D., Nye, G., Uknes, S. Ward, E., Kessmann, H., and Ryals, J. 1993. Requirement of salicylic acid for the induction of systemic acquired resistance. Science 261:754-756.

Genoud, T., Buchala, A. J., Chua, N. H., and Metraux, J. P. 2002. Phytochrome signaling modulates the SA-perceptive pathway in Arabidopsis. Plant J. 31:87-95.

Gorlach, J., Volrath, S., Knauf-Beiter, G., Hengy, G., Beckhov,e U., Kogel, K. H., Oostendorp, M., Staub, T., Ward, E., Kessmann, H., and Ryals, J. 1996. Benzothiadiazole, a novel class of inducers of systemic acquired resistance, activates gene expression and disease resistance in wheat. Plant Cell 4:629-643.

Gray, J., Close, P. S., Briggs, S. P., and Johal, G. S. 1997. A nove suppressor of cell death in plants encoded by the Lls1 gene of maize. Cell 89:25-31.

Gray, J., Janick-Buckner, D., Buckner, B., Close, P. S., and Johal, G. S. 2002. Light-dependent death of maize $l l s 1$ cells is mediated by mature chloroplasts. Plant Physiol. 130:1894-1907.

Greenberg, J. T., Silverman, F. P., and Liang, H. 2000. Uncoupling salicylic acid-dependent cell death and defense-related responses from disease resistance in the Arabidopsis mutant acd5. Genetics 156:341350

Jabs, T. 1999. Reactive oxygen intermediates as mediators of programmed cell death in plants and animals. Biochem Pharmacol. 57:231-245.

Jabs, T., Deitrich, R. A., and Dangle J. L. 1996. Initiation of runaway cell death in an Arabidopsis mutant by extracellular superoxide. Science 273:1853-1856

Jambunathan, N., Siani, J. M., and McNellis, T. W. 2001. A humiditysensitive Arabidopsis copine mutant exhibits precocious cell death and increased disease resistance. Plant Cell 13:2225-2240.

Kinkema, M., Fan, W., and Dong, X. 2000 Nuclear localization of NPR1 is required for activation of PR gene expression. Plant Cell 12:23392350.

Kiyosawa, S. 1970. Inheritance of a particular sensitivity of the rice variety Sekiguchi Asahi, to pathogens and chemicals, and linkage relationship with blast resistance. Bull. Nat. Agric. Sci. (Jpn.) Ser. D. Physiol. Genet. 21:61-71.

Kohler, A., Schwindling, S., and Conrath, U. 2002. Benzothiadiazoleinduced priming for potentiated responses to pathogen infection, wounding, and infiltration of water into leaves requires the NPR1/NIM1 gene in Arabidopsis. Plant Physiol. 128:1046-1056.

Lawton, K. A., Friedrich, L., Hunt, M., Weymann, K., Delaney, T., Kessmann, H., Staub, T., and Ryals, J. 1996. Benzothiadiazole induces disease resistance in Arabidopsis by activation of the systemic acquired resistance signal transduction pathway. Plant J. 1:71-82.

Lee, M. W., Qi, M., and Yang, Y. 2001. A novel jasmonic acid-inducible rice $m y b$ gene associates with fungal infection and host cell death. Mol. Plant-Microbe Interact. 14:527-535.

Lorrain, S., Valileau, F., Balague, C., and Roby, D. 2003. Lesion mimic mutants: keys for deciphering cell death and defense pathways in plants. Trends Plant Sci. 8:263-271.

Malamy, J., Carr, J. P., Klessig, D. F., and Raskin, I. 1990. Salicylic acid: A likely endogenous signal in the resistance response of tobacco to viral infection. Science 250:1002-1004.

Maleck, K., Levine, A., Eulgem, T., Morgan, A., Schmid, J., Lawton, K A., Dangl, J. L., and Dietrich, R. A. 2000. The transcriptome of Arabidopsis thaliana during systemic acquired resistance. Nat. Genet. 4:403-410.
McGee, J. D., Hamer, J. E., and Hodges, T. K. 2001. Characterization of $P R-10$ pathogenesis-related gene family induced in rice during infection with Magnaporthe grisea. Mol. Plant-Microbe Interact. 14:877-886.

Metraux, J.-P., Signer, H., Ryals, J., Ward, E., Wyss-Benz, M., Gaudin, J., Raschdorf, K., Schmid, E., Blum, W., and Inveradi, B. 1990. Increase in salicylic acid at the onset of systemic acquired resistance in cucumber. Science 250:1004-1006.

Midoh, N., and Iwata, M. 1996. Cloning and characterization of a probenazole-inducible gene for an intracellular pathogenesis-related protein in rice. Plant Cell Physiol. 37:9-18.

Morris, K., MacKerness, S. A., Page, T., John, C. F., Murphy, A. M., Carr, J. P., and Buchanan-Wollaston, V. 2000. Salicylic acid has a role in regulating gene expression during leaf senescence. Plant J. 23:677685.

Morris, S. W., Vernooij, B., Titatarn, S., Starrett, M., Thomas, S., Wiltse, C. C., Frederiksen, R. A., Bhandhufalck, A., Hulbert, S., and Uknes, S 1998. Induced resistance responses in maize. Mol. Plant-Microbe Interact. 11:643-658.

Mou, Z., Fan, W., and Dong, X. 2003. Inducers of plant systemic acquired resistance regulate NPR1 function through redox changes. Cell 113:935-944.

Nishizawa, Y., Saruta, M., Nakazono, K., Nishio, Z., Soma, M., Yoshida T., Nakajima, E., and Hibi, T. 2003. Characterization of transgenic rice plants over-expressing the stress-inducible beta-glucanase gene Gns1. Plant Mol. Biol. 51:143-152.

Oostendorp, M., Kunz, W., Dietrich, B., and Staub, T. 2001. Induced disease resistance in plants by chemicals. Eur. J. Plant Pathol. 107:1928

Pieterse, C. M., van Wees, S. C., van Pelt, J. A., Knoester, M., Laan, R., Gerrits, H., Weisbeek, P. J., and van Loon, L. C. 1998. A novel signaling pathway controlling induced systemic resistance in Arabidopsis. Plant Cell 10:1571-1580.

Pilloff, R. K., Devadas, S. K., Enyedi, A., and Raina, R. 2002. The Arabidopsis gain-of-function mutant dll1 spontaneously develops lesions mimicking cell death associated with disease. Plant J. 30:61-70.

Ryals, J. A., Neuenschwander, U. H., Willits, M. G., Molina, A., Steiner, H-Y., and Hunt, M. D. 1996. Systemic acquired resistance. Plant Cell 8:1809-1819.

Ryals, J., Weymann, K., Lawton, K., Friedrich, L., Ellis, D., Steiner, H-Y. Johnson, J., Delaney, T. P., Jesse, T., Vos, P., and Uknes. S. 1997. The Arabidopsis NIM1 protein shows homology to the mammalian transcription factor inhibitor I kappa B. Plant Cell 9:425-439.

Sambrook , J., Fritsch, E. F., and Maniatas, T. 1989. Molecular Cloning: A Laboratory Manual. 2nd ed. Cold Spring Harbor Laboratory, Cold Spring Harbor, NY

Schweizer, P., Schlagenhauf, E., Schaffrath, U., and Dudler, R. 1999. Different patterns of host genes are induced in rice by Pseudomonas syringae, a biological inducer of resistance, and the chemical inducer benzothiadiazole (BTH). Eur. J. Plant Pathol. 105:659-665.

Shah, J., Kachroo, P., and Klessig, D. F. 1999. The Arabidopsis ssil mutation restores pathogenesis-related gene expression in $n p r l$ plants and renders defensin gene expression salicylic acid dependent. Plant Cell 11:191-206.

Shah, J., Kachroo, P., Nandi, A., and Klessig, D. F. 2001. A recessive mutation in the Arabidopsis SSI2 gene confers SA- and NPRIindependent expression of PR genes and resistance against bacterial and oomycete pathogens. Plant J. 25:563-574.

Shah, J., Tsui, F., and Klessig D. F. 1997. Characterization of a salicylic acid-insensitive mutant (sail) of Arabidopsis thaliana, identified in a selective screen utilizing the SA-inducible expression of the tms 2 gene. Mol. Plant-Microbe Interact. 10:69-78

Shirano, Y., Kachroo, P., Shah, J., and Klessig, D. F. 2002. A gain-offunction mutation in an Arabidopsis Toll Interleukin1 receptornucleotide binding site-leucine-rich repeat type $\mathrm{R}$ gene triggers defense responses and results in enhanced disease resistance. Plant Cell 4:31493162.

Silverman, P., Seskar, M., Kanter, D., Schweizer, P., Metraux, J-P., and Raskin, I. 1995. Salicylic acid in rice: biosynthesis, conjugation and possible role. Plant Physiol. 108:633-639.

Smith, J. A., and Metraux, J.-P. 1991. Pseudomonas syringae pathovar syringae induces systemic resistance to Pyricularia oryzae in rice. Physiol. Mol. Plant Pathol. 39:451-461.

Spoel, S. H., Koornneef, A., Claessens, S. M., Korzelius, J. P., Van Pelt, J. A., Mueller, M. J., Buchala, A. J., Metraux, J-P., Brown. R., Kazan, K., Van Loon, L. C., Dong, X., and Pieterse, C. M. 2003. NPR1 modulates cross-talk between salicylate- and jasmonate-dependent defense pathways through a novel function in the cytosol. Plant Cell 15:760-770.

Subramaniam, R., Desveaux, D., Spickler, C., Michnick, S. W., and Brisson, 
N. 2001. Direct visualization of protein interactions in plant cells. Nat. Biotechnol. 19:769-772.

Takahashi, A., Kawasaki, T., Henmi, K., Shii, K., Kodama, O., Satoh, H., and Shimamoto, K. 1999. Lesion mimic mutants of rice with alterations in early signaling events of defense. Plant J. 17:535-545.

Vernooij, B., Friedrich, L., Morse, A., Reist, R., Kolditz-Jawhar, R., Ward, E., Uknes, S., Kessman, H., and Ryals, J. 1994. Salicylic acid is not the translocated signal responsible for inducing systemic acquired resistance but is required in signal transduction. Plant Cell 6:959-965.

Ward, E. R., Uknes, S. J., Williams, S. C., Dinsher, S. S., Wiederhold, D.
L., Alexander, D. C., Ahl-Goy, P., Metraux, J.-P., and Ryals, J. A. 1991. Coordinate gene activity in response to agents that induce systemic acquired resistance. Plant Cell 3:1085-1094.

Yin, Z., Chen, J., Zeng, L., Goh, M., Leung, H., Khush, G., and Wang, G.L. W. 2000. Characterizing rice lesion mimic mutants and identifying a mutant with broad-spectrum resistance to rice blast and bacterial blight. Mol. Plant-Microbe Interact. 13:869-876.

Zhang, Y., Fan, W., Kinkema, M., Li, X., and Dong, X. 1999. Interaction of NPR1 with basic Leucine zipper protein transcription factors that bind sequences required for salicylic acid induction of the $P R-1$ gene. Proc. Natl. Acad. Sci. U.S.A. 96:6523-6528. 